http://jmscr.igmpublication.org/home/

ISSN (e)-2347-176x ISSN (p) 2455-0450

crossref DOI: https://dx.doi.org/10.18535/jmscr/v8i10.22

Journal Of Medical Science And Clinical Research

\title{
Classical Manifestations of Gorlin-Goltz Syndrome in an Operated Case of Medulloblastoma: A Case Report
}

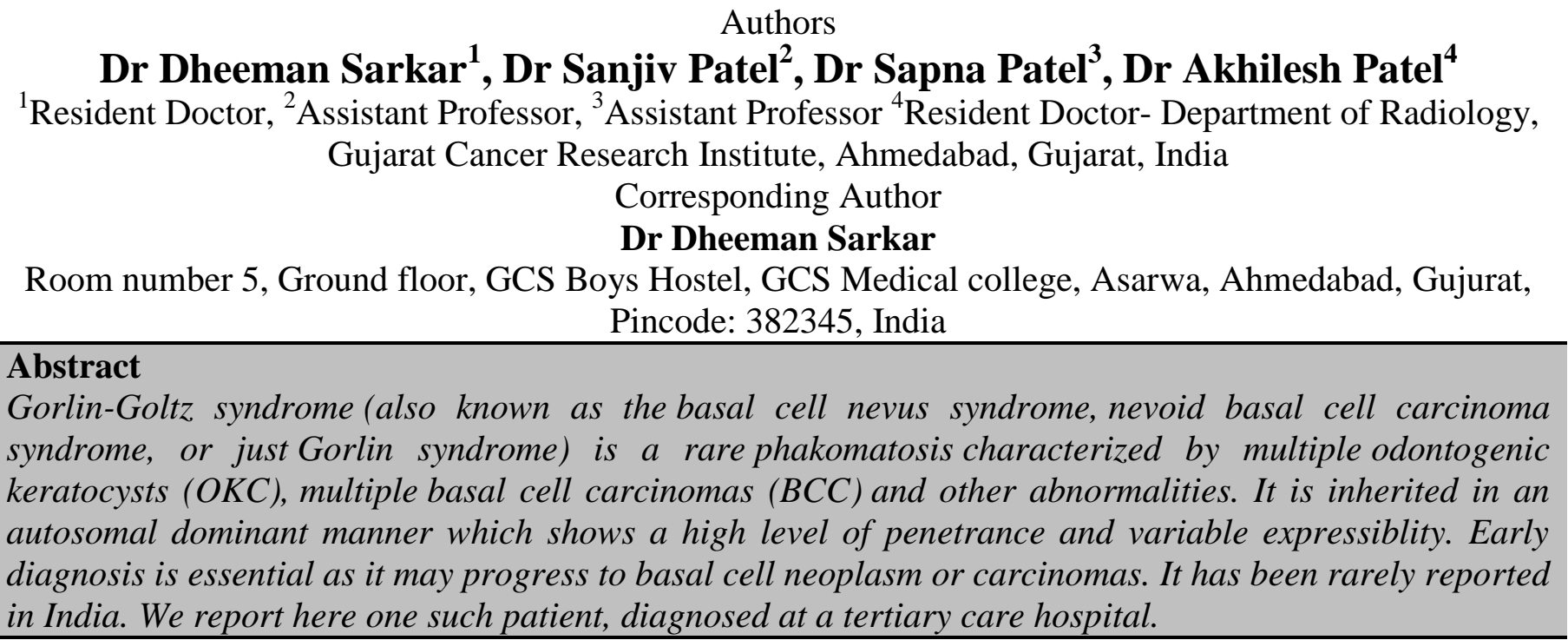

\section{Introduction}

Gorlin-Goltz syndrome is an infrequent multisystem disease characterized by keratocystic odontogenic tumors in the jaw, multiple basal cellnevi carcinomas and skeletal abnormalities. ${ }^{(1)}$ It is due to a mutation in PTCH tumor suppressor gene located on chromosome $9^{(2)}$, which encodes for the "Sonic Hedgehog" receptor. ${ }^{(3)}$ This condition is quite rare in the Indian subcontinent. This condition occurs in approximately 1 in 60,000 live births while $0.4 \%$ of patients with basal cell carcinoma are estimated to have GorlinGoltzsyndrome. $^{(4)}$ It is a multidisciplinary problem, early diagnosis of which allows introduction of secondary prophylaxis and following appropriate treatment to delay the progress of the syndrome. ${ }^{(2)}$
This is a case report describes the multimodality approach in a patient with Gorlin-Goltz syndrome.

\section{Case Report}

In the year 2004, a one and half year old girl, previously in good health, started having crying spells while standing upright or walking, which were only relieved after lying down. The patient was suspected to have some pathology in the brain for which she came to GCRI (Gujarat Cancer Research Institute), Ahmedabad - A tertiary care cancer institute in western India, for diagnosis and further management. The attending physician after examining her ordered a CT scan of the brain, which revealed a posterior fossa tumour with obstructive hydrocephalus. She underwent midline suboccipital craniotomy surgery and got it removed, which on biopsy revealed it to be- 
medulloblastoma. The surgery was followed by radiotherapy for the next three months. She regain normalcy and went back to her routine life.

Seven years later in 2011, she develops abdominal distension. On examination there was a palpable pelvic mass extending uptothe epigastric region. She underwent a CT scan of the abdomen and pelvis region, which revealed a well-defined mild heterogeneously enhancing soft tissue density lesion arising from pelvis. Biopsy from this mass was done which revealed it to be - ovarian fibroma. The ovarian fibroma was operated and removed as these tumours are notorious for complications like ovarian torsion in the future. Following this, her parents started to notice that their daughter had started to show features of stunted growth and in general an abnormal body structure.

Four years later in 2015, she complained of multiple pigmented cutaneous lesions in sun exposed parts of her body primarily in face and scalp region and experienced two episodes of seizures in a 24 hourtime frame. A skin biopsy was done which showed that those lesions were Nevoid basal cell carcinoma. Further radiological evaluation showed recurrence of medulloblastoma for which she underwent a repeat craniotomy. With this revelation, the clinician suspected a syndromic association, and ordered a battery of other tests, from which a diagnosis of - GorlinGoltz syndrome was made.

4 years later in 2019, a follow up MRI brain scan was done which revealed analtered signal intensity lesion in the frontal lobe region. It showed underlying hyperostosis of the right frontal bone and showed intense post contrast enhancement. Radiologically this was probably a newly developed meningioma. It also showed leptomeningeal enhancement noted in b/l cerebral hemispheres and along visualised spinal cord which was probably due to the a past history of medulloblastoma.

Her present day condition is such that clinically as well as radiologically she exhibits florid features of Gorlin-Goltz syndrome and is being treated symptomatically.
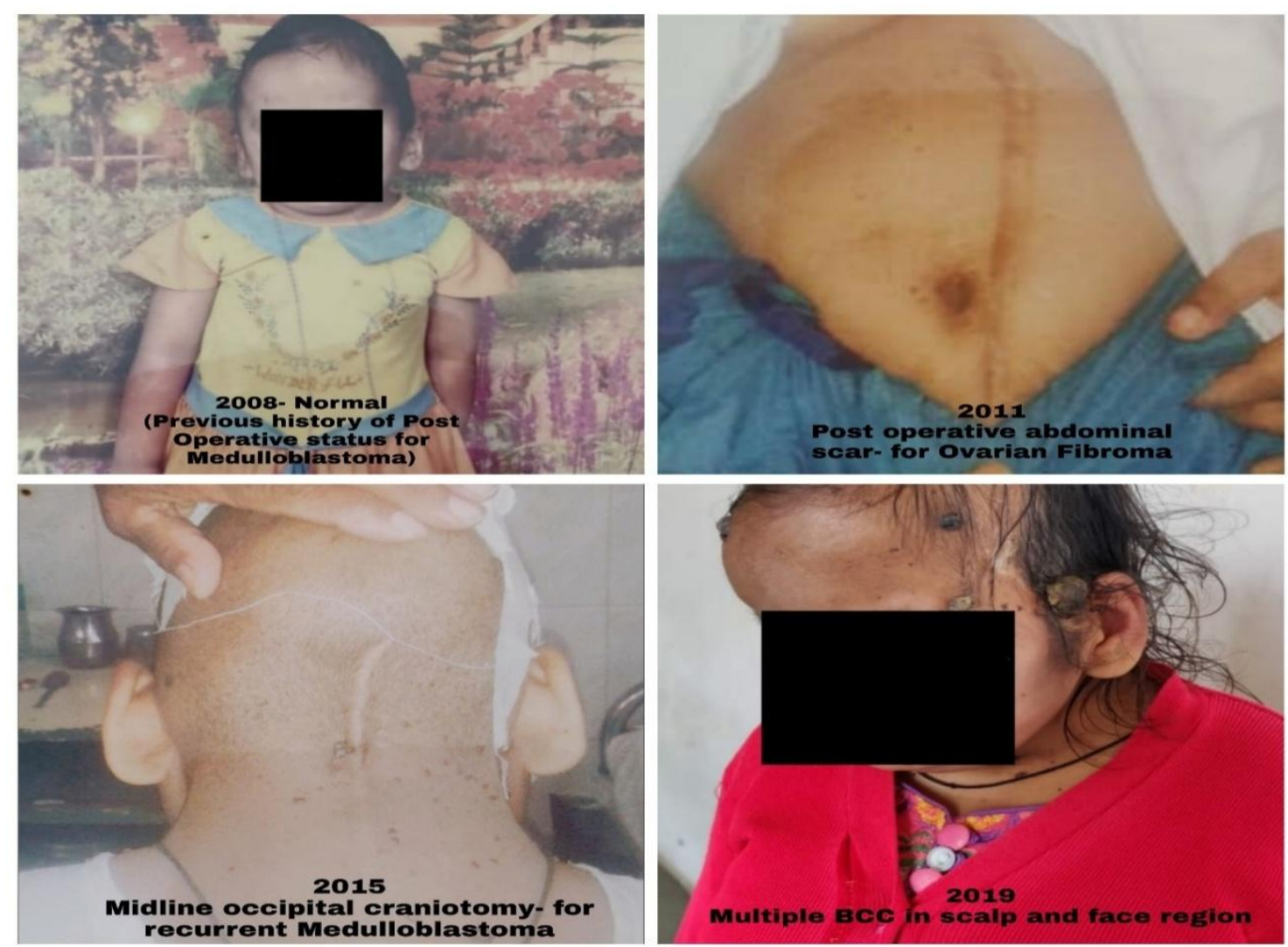

Figure 1: The chronology of the events in the patient's life that lead to the diagnosis of - Gorlin Goltz syndrome. 


\section{JMSCR Vol||08||Issue $\|10\|$ Page 160-164||October}

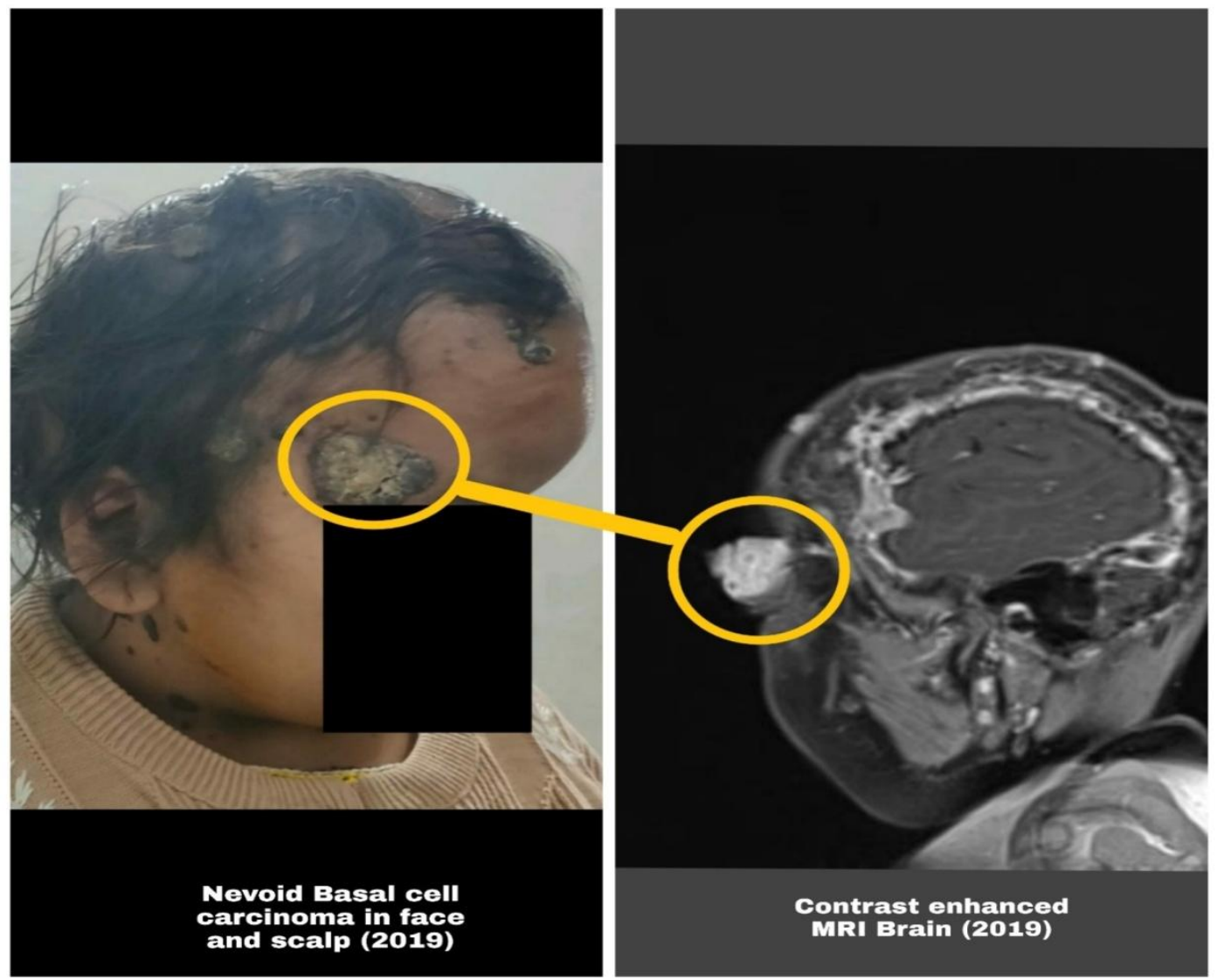

Figure 2: Nevoid basal cell carcinoma (Real life and its MRI Appearance)- Included as one of the major criteria for the diagnosis of GorlinGoltz syndrome.

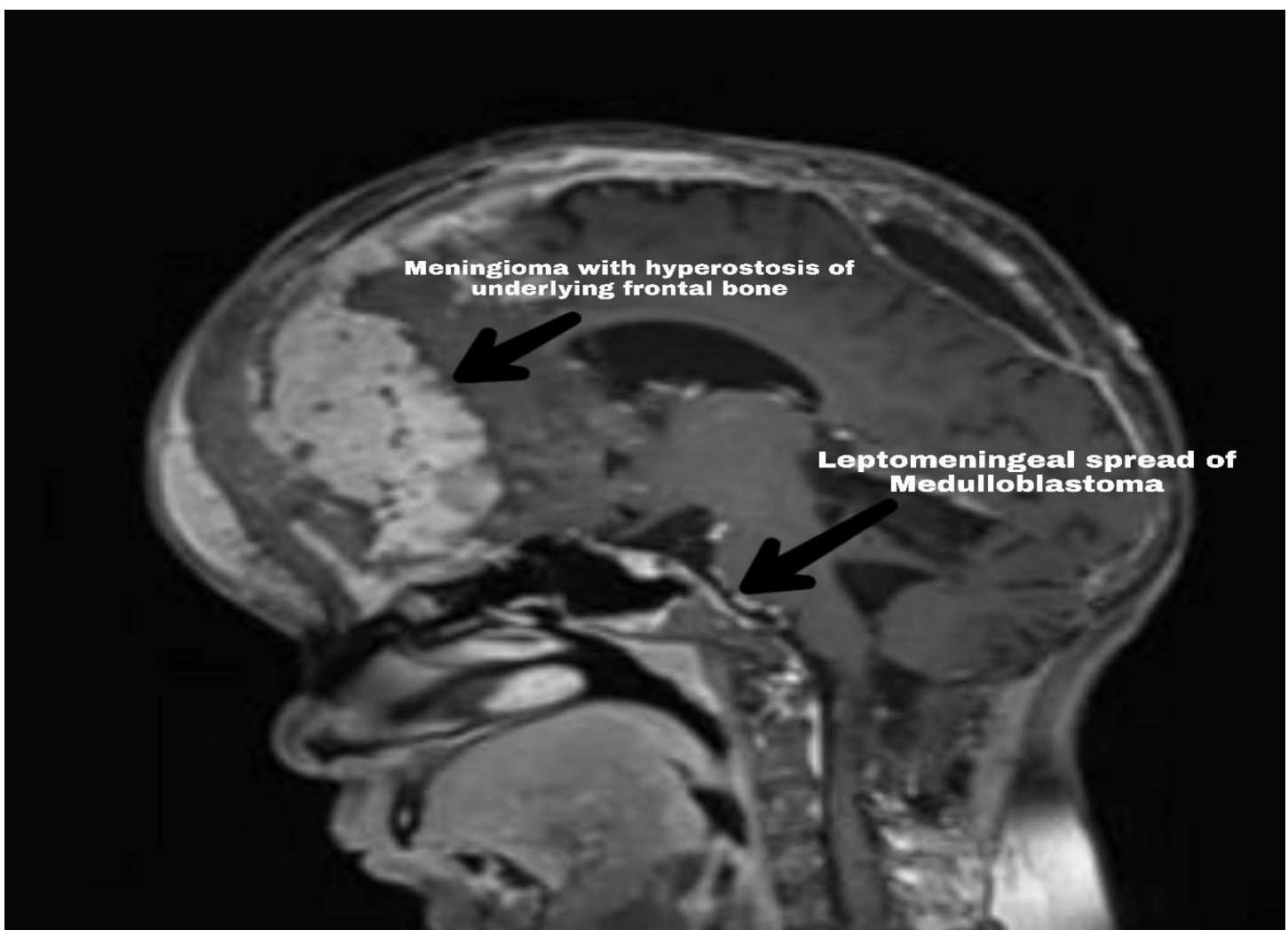

Figure 3: New development of meningioma in the frontal lobe region with leptomeningeal spread over brain and visualised spinal cord due to previously operated medulloblastoma rendering the case to be inoperable. 


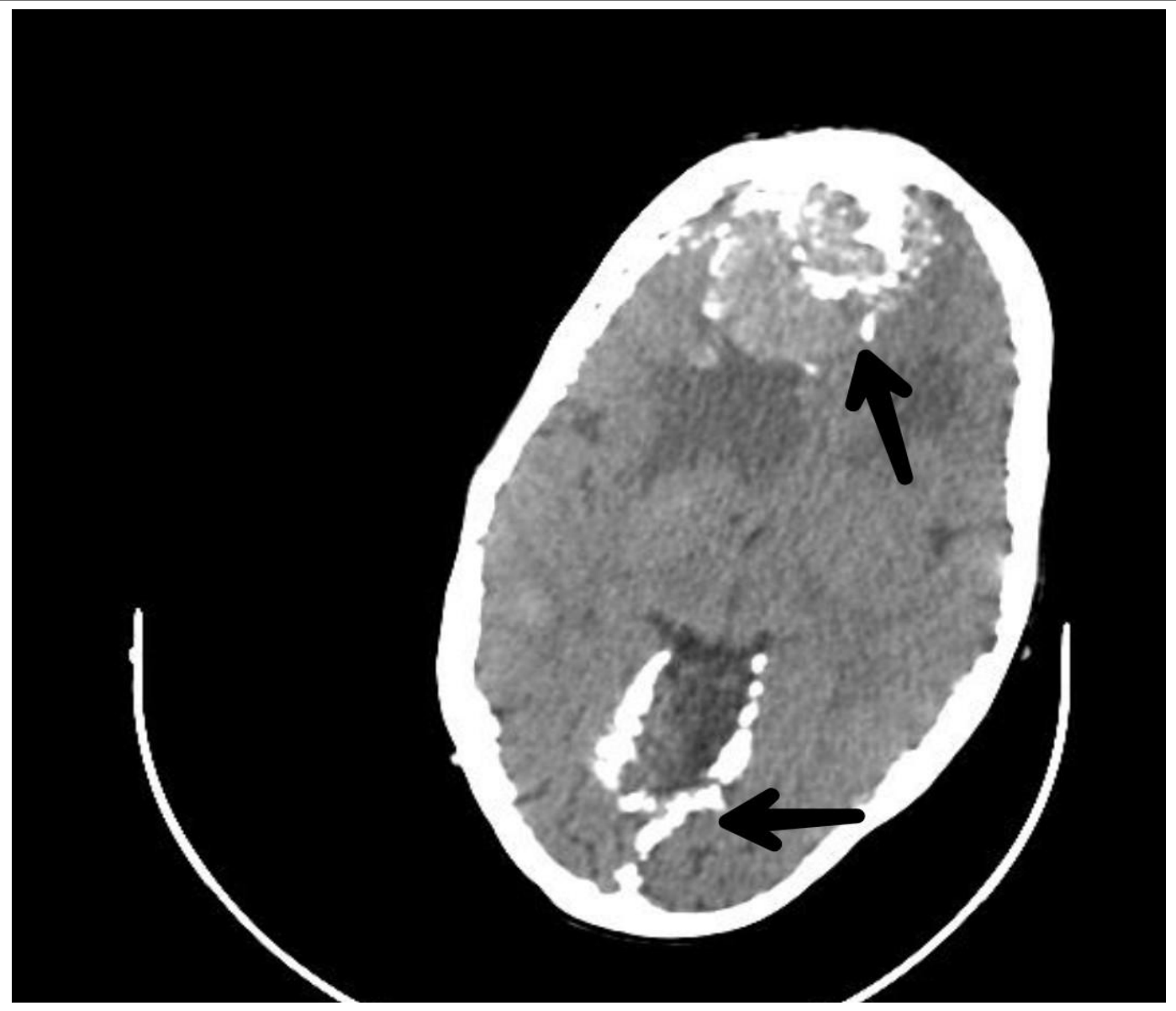

Figure 4: CT scan of the brain revealingfalx cerebri calcifications and coarse calcifications noted in the frontal lobe meningioma.
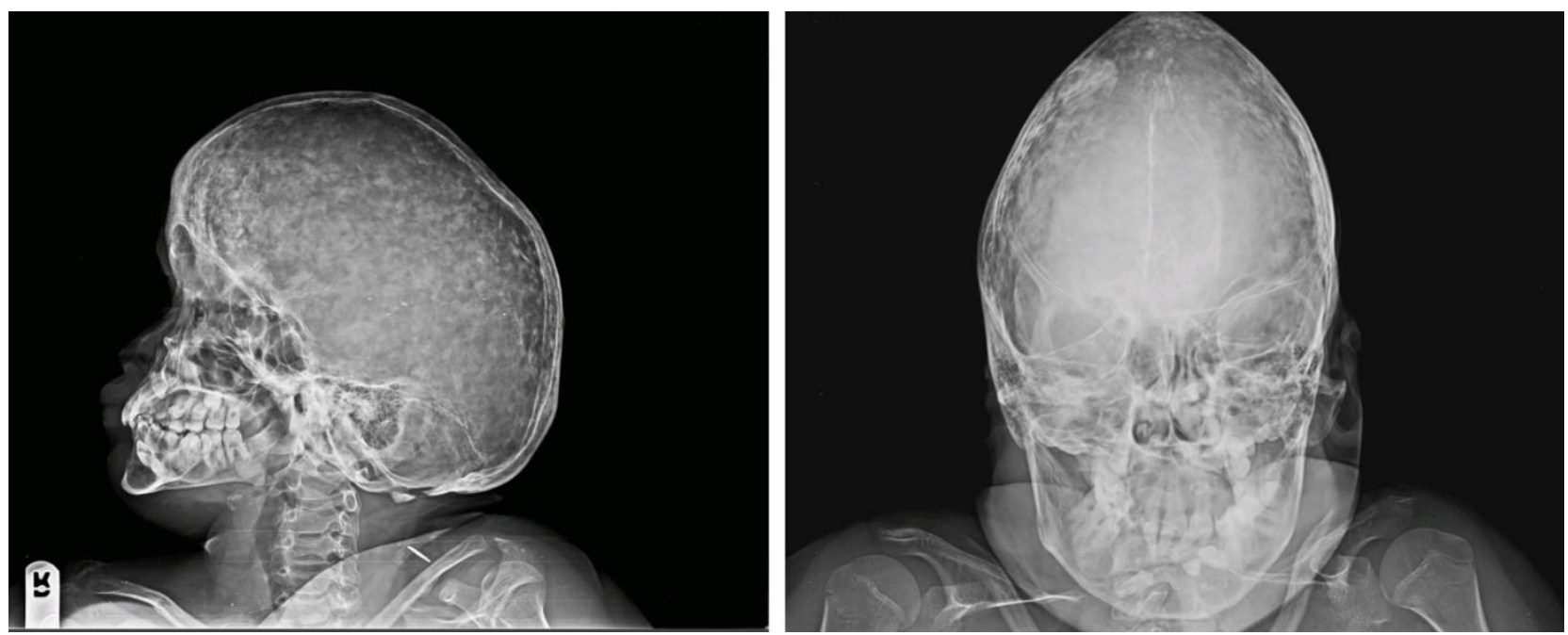

Figure 5 : Skull x- ray- AP and Lateral view.

(Note: I hereby declare that all the above images are original)

\section{Discussion}

The name Gorlin syndrome refers to the American oral pathologist and human geneticist Robert J. Gorlin (1923-2006). ${ }^{(5)} \quad$ The American dermatologist Robert W. Goltz (1923$2014)^{(6)}$ was his co-author, which is the basis for the term 'Gorlin-Goltz syndrome'. First described in 1960 by Gorlin and Goltz, as a distinct syndrome, consisting of the presence of multiple nevoid basal cell epitheliomas, jaw cysts and bifid ribs. In addition to the classical triad described by Gorlin and Goltz, calcification of the falxcerebri, 
palmar and plantar epidermal pits, spine and rib anomalies, relative macrocephaly, facial milia, frontal bossing, ocular malformation, medulloblastomas, cleft lip and/or palate, and developmental malformations have also been established as features of the syndrome. ${ }^{(7-9)}$ In the case of GGS it is important to make an early diagnosis as these patients show increased propensity to multiple malignant neoplasms and are also sensitive to ionizing radiation including UV radiation. ${ }^{(10)}$

A clinical diagnosis can be made using major and minor criteria established by Evans et Al. and modified by Kimonos et al. Either two major or one major criteria must be met. The major criteria includes basal cell carcinoma: > 2 or 1 under the age 20, palmar pits (3 or more), odontogenic keratocytes, bilamellar calcifications of the falxcerebri, rib anomalies: Bifid ribs, fused, splayed, first degree relative with Gorlin syndrome. The minor criteria includes macrocephaly, frontal bossing, medulloblastoma, cleft lip or hypertelorism, sprengels deformity, flame-shaped osseous radiolucencies, pectumexcavatum or pectus carinatum, syndactyly, bridging of the sellaturcica, hemivertebrae and ovarian fibroma.

Owing to the familial tendency of this condition, the family members are also asked to undergo thorough clinical and radiological examination.

\section{Conclusion}

This case emphasizes the role of a radiologist in recognizing these features on imaging in order to get early diagnosis with a multimodality approach. A myriad of typical findings were seen in various imaging modalities in this patient, especially in CT scan and MRI of the brain of this patient. The patients affected by Gorlin-Goltz syndrome must be evaluated by several relevant specialists to precisely confirm the diagnosis, detect the likely genetic basis, provide appropriate genetic counselling, and manage the various clinical manifestations. Early diagnosis and treatment may reduce the severity of the long term sequelae of
Gorlin-Goltz syndrome including malignancy and oromaxillofacial deformation and destruction. Also, regular follow up by multispecialist team should be carried out to monitor the syndrome.

\section{References}

1. Ana $\mathrm{R}$ Casaroto, Daniela $\mathrm{CN}$ Rocha Loures, Vanessa S Lara.Early diagnosis of gorlin- goltz syndrome: a case report. Head and Face Medicine 2009;

2. Padma Pandeshwar,K. Jayanthi, and D. Mahesh. Gorlin-goltz syndrome. Dentistry 2012;

3. Brelier F et al. Ultraviolet responses of Gorlin syndrome primary skin cells. Dermatology, 2008; 445-452

4. Ian Bickle, Gagandeep Singh et al.Gorlingoltz syndrome. Radiology. 2010; 5794

5. Burgdorf W. Robert J. Gorlin, Löser C, Plewig G, Hrsg, Pantheon derdermatologie. 2008: 362-366

6. Burgdorf WH, Padilla RS, Hordinsky M. In memoriam: Robert W. Goltz. Dermatology. 2014; 71:163-165

7. L. Lo Muzio. Nevoid basal cell carcinoma syndrome (Gorlin syndrome). RareDiseases. 2008;

8. V. E. Kimonis, A. M. Goldstein, B. Pastakia et al. Clinical manifestations in 105 persons with nevoid basal cell carcinoma syndrome. Medical Genetics. 1997;

9. N. Santana, B. K. Yashodha Devi, and D. Jatti. Gorlin Goltz syndrome-a case report. Dental. 2011;

10. M. Ljubenovi, D. Ljubenovi, I. Bini, D. Jovanovi, and M. Stanojevi. Gorlin-Goltz syndrome. Dermatology. 2007; 